\title{
Future perspectives of fertility preservation in women
}

\author{
Bettina Böttcher (1) · Katharina Winkler-Crepaz
}

Received: 3 April 2020 / Accepted: 28 May 2020 / Published online: 23 June 2020

(C) The Author(s) 2020

\begin{abstract}
Summary Fertility preservation in women has become well established over the last two decades. Nevertheless, options for cancer survivors need to be improved to regain ovarian functioning, ideally leading to pregnancy and live birth. Techniques to protect the ovary from the damage of cytotoxic agents, to improve the survival of follicles in the ovarian graft, and to minimize the risk of re-seeding malignant cells after ovarian tissue transplantation are the object of current research all over the world. The demand for fertility preservation procedures in patients with benign diseases like systemic lupus erythematosus before cytotoxic therapy, in patients with endometriosis before surgery, and in patients with genetic predispositions which can lead to a premature ovarian failure will further increase in coming years. In this short review, these future perspectives are presented.
\end{abstract}

Keywords Cancer survivors · Artificial ovary $\cdot$ In vitro maturation · Follicular survival · Ovarian tissue cryopreservation

\section{Introduction}

Despite rapid progress in fertility preservation techniques, existing applications need to be improved. Worldwide research continues to focus on developing agents which could protect the ovaries during cytotoxic therapy and minimize gonadal damage

\section{B. Böttcher, MD, MA (ه)}

Department of Gynecological Endocrinology and

Reproductive Medicine, Medical University of Innsbruck, Anichstraße 35, 6020 Innsbruck, Austria

bettina.boettcher@i-med.ac.at

K. Winkler-Crepaz, MD

Department of Obstetrics and Gynecology, Paracelsus Medical University, Müllner Hauptstraße 48, 5020 Salzburg, Austria
(Sect. Gonadoprotective agents), on enhancing follicular survival after implantation of the ovarian graft (Sect. Increasing follicular survival after implantation of the ovarian graft) and on reducing the risk of reimplanting malignant cells which might be present in the ovarian graft (Sect. Reducing the risk of re-implanting malignant cells). This risk could possibly be reduced by two different methods: a system of in vitro growth (IVG) for primordial follicles (Sect. In vitro growth and maturation of primordial follicles) and the transplantation of an artificial ovary containing isolated follicles which are embedded in a matrix (Sect. Artificial ovary). In addition, stem cells (Sect. Stem cells) and allografting and xenotransplantation of ovarian tissue (Sect. Allografting and xenotransplantation) might offer completely new options. Benign diseases which require cytotoxic therapy, genetic predispositions leading to a diminished ovarian reserve or trans*persons before hormone therapy represent further indications for procedures of fertility preservation which will be more and more asked for (Sect. Further indications for fertility preservation). Future enhancements are to be expected in methods offered to prepuberal girls.

\section{Gonadoprotective agents}

The mechanism of potential gonadoprotective agents is based on the theory that follicle loss induced by chemotherapy is caused by apoptosis of large follicles and, simultaneously, by activation of dormant follicle growth. Therefore, the focus of current research is on agents with anti-apoptotic characteristics or being able to prevent follicle activation: sphingosine1-phosphate (S1P) was found to block apoptosis induced by certain cytotoxic drugs and to protect follicles against radiation in animal studies via inhibition of the ceramide-promoted pathway [1-3]. However, 
this agent can currently not be administered systemically due to its short half-life, which limits its use [4].

Imatinib is a c-Abl tyrosine kinase inhibitor which was found to protect ovarian follicles in mice when co-administered with cisplatin [5].

Tamoxifen, a selective estrogen receptor modulator is well known in the field of treating estrogen-sensitive cancers like breast cancer. After co-administration with doxorubicin and cyclophosphamide in rats, tamoxifen was found to reduce follicle loss and oocyte fragmentation [6]. It also had an effect on radiotherapy-induced follicular loss in rats by acting via stabilizing the anti- Mullerian hormone (AMH) level, increasing insulin-like growth factor (IGF-1) and counteracting oxidative stress mediating apoptosis [7].

The immune modulator AS101 prevents follicle activation by inhibiting the PI3K/PTEN/Akt signaling pathway and thereby prevents the "burnout" effect of chemotherapy. AS101 has been co-administered with cyclophosphamide in mice: primordial follicle activation was inhibited and follicle reserve was preserved. Interestingly, the efficacy of cyclophosphamide on breast cancer cells was increased [8]. Melatonin, ghrelin and mTOR inhibitors have also been found to inhibit accelerated activation of primordial follicles in co-administration with cisplatin [9]. Two different pharmacologic approaches to inhibit the mTOR pathway-everolimus (RAD001) and rapamycin-have been shown to preserve the ovarian reserve. These promising results with the established drug everolimus were obtained in mice treated with cisplatin in which the PI3K/PTEN/Akt pathway was involved [9].

\section{Increasing follicular survival after implantation of the ovarian graft}

Cryopreservation of ovarian tissue and later transplantation to the ovary has become a promising technique with over 130 live births worldwide [10]. Nevertheless, after transplantation extensive follicular loss has been observed. It is hypothesized that slow graft revascularization leads to ischemia which causes follicular loss [11]. Therefore, several novel techniques are being explored to increase vascularization with angiogenic and antiapoptotic agents. The following substances have been administered to the frozen-thawed ovarian tissue with promising results: a combination of melatonin, vitamin $\mathrm{E}$, hyaluronan, and vascular endothelial growth factor $\mathrm{A}$ (VEGF-A) increased neovascularization and reduced apoptosis [11]. Furthermore, experimental designs with erythropoietin, VEGF111, fibroblast growth factor, simvastatin, and a subcutaneous pump with S1P have shown promising results in decreasing follicular apoptosis [4]. Two pregnancies and one live birth have been reported after transplantation of ovarian tissue with a decellularized extracellular matrix (ECM) which led to the survival of primordial follicles [12].

\section{Reducing the risk of re-implanting malignant cells}

\section{In vitro growth and maturation of primordial follicles}

Transplantation of frozen-thawed ovarian tissue contains the risk of re-seeding malignant cells into the patient. In vitro growth (IVG) of follicles and in vitro maturation (IVM) of oocytes minimizes this risk. The aim of IVG is to accomplish the entire follicular growth in vitro, ending with oocytes which can be fertilized. To date, follicular IVG has led to live births in mice only $[13,14]$. Several culture systems have been developed for ovarian tissue and follicles [13, 15-18]. As different follicular stages require different culture environments, the development of a well-functioning culture system remains challenging. Furthermore, the morphology of the follicles and critical cell-cell interactions need to be maintained [19]. The ideal matrix for the growth of primordial follicles is still unknown. Although different growth factors have been added to the culture systems, the development of follicles often stopped at early secondary follicle stage [4].

A two-step culture system was established by Telfer et al. [17]. This system first initiates the growth of primordial follicles and afterwards cultures secondary follicles which have been isolated in an individual culture, allowing growth until the preantral/early antral stage. The same research group recently presented the growth of human metaphase II oocytes in a multistep culture system [20]. Other promising results were based on implementing a three-dimensional alginate hydrogel matrix which allowed the follicles to maintain their physiologic structure. Secondary follicles were isolated and cultured up to 40 days, oocytes were isolated and in vitro maturated [21]. However, IVG of meiotically competent human oocytes from preantral follicles has not been achieved [21].

Further research has shown that follicle activation can be achieved by interrupting the Hippo signaling pathway and/or inhibiting the PI3K-PTEN-Akt signaling pathway in prepuberal patients and women with premature ovarian insufficiency (POI) [22]. As PTEN expression was reduced after xenografting of human ovarian tissue, it was hypothesized that primordial follicle loss after ovarian transplantation might be due to disruption of PI3K/Akt signaling [23]. These two signaling pathways seem to play key roles in the activation of primordial follicles. The PI3K-PTEN-Akt pathway takes part in the regulation of follicle dormancy by keeping high levels of the secondary messenger phosphatidylinositol-4,5-bisphosphate (PIP2) in relation to lower levels of phosphatidylinositol-3,4,5triphosphate (PIP3). Incubation of frozen-thawed tissue with substances which elevate PIP3 levels has led to three clinical pregnancies after implanting the ovarian graft [24-26].

The Hippo pathway is involved in cell proliferation, apoptosis, follicular development, and is essential for 
organ size control $[22,27]$. If the pathway is disrupted, cell growth and proliferation is promoted as it occurs during the slicing procedure of ovarian tissue. This fragmentation led to the development of preantral follicles [22] and, after administration of Akt stimulators to the culture system, to the growth of primordial follicles in patients suffering from POI [24].

In conclusion, although these are promising results, it remains to be confirmed that the in vitro maturated oocytes are competent to complete maturation processes and genomic imprinting procedures [19] and, in the end, safe for clinical implications.

\section{Artificial ovary}

The generation of a transplantable artificial ovary is another alternative to the in vitro culture of follicles in order to obtain mature oocyte and to minimize the risk of re-seeding malignant cells. For this technique, primordial follicles need to be isolated and transferred onto a three-dimensional scaffold with alginate, fibrin, gelatin, or polyethylene glycol [28-32]. Preantral follicles were embedded in an alginate beads and grafted to immunocompetent mice. It could be shown that antral follicles were capable of growing in this matrix [31]. The artificial ovary requires stroma cells which might still bear the risk of containing cancer cells: fresh human medullary cells turned out to be an efficient source [33].

\section{Stem cells}

The use of embryonic stem cells or induced pluripotent stem cells might be another source of gametes but it is still questionable whether these cells would be able to cope with complex mechanisms involved in genomic imprinting and epigenetic procedures [10, $34,35]$.

\section{Allografting and xenotransplantation}

Transplantation of ovarian tissue between two different individuals - under caution of compatibility also applying to transplantation of other organs-could be another potential option to regain ovarian function and possibly natural conception. This procedure has been performed between two sisters and led to the first published live birth after allografting ovarian tissue [36]. Another option to minimize the risk of transplanting malignant cells would be the xenotransplantation of cryopreserved tissue into another species in order to maturate oocytes and to transfer them to patients after fertilization [37].

\section{Further indications for fertility preservation}

Autoimmune diseases which might require cytotoxic therapy like systemic lupus erythematosus are further indications for fertility preservation procedures.
Furthermore, genetic predispositions like Turner syndrome can lead to premature ovarian failure. In these women procedures could be offered before the ovarian reserve is diminished. Due to the rapid advancements in improving techniques, it is assumable that more options will soon be available for prepuberal girls. Before surgery including the resection of ovarian tissue in patients with endometriosis, women could be counselled about fertility preservation techniques. In addition, the demand for cryopreservation of oocytes or ovarian tissue by trans*persons before the start of hormone therapy is increasing.

\section{Take home message}

- Gonadoprotective agents aim to prevent the chemotherapy-induced loss of follicles mainly by anti-apoptotic characteristics or prevention of follicle activation.

- Increasing follicular survival after implantation of the frozen-thawed ovarian tissue can possibly be achieved by co-administration of different substances like VEGF, S1P or with an extracellular matrix.

- The risk of re-seeding malignant cells after frozenthawed ovarian tissue transplantation might be minimized by in vitro growth and maturation of primordial follicles and oocytes or generation of an artificial ovary.

- However, it remains to be confirmed that in vitro maturated oocytes are competent to complete maturation processes and genomic imprinting procedures and safe for clinical implications.

Funding Open access funding provided by University of Innsbruck and Medical University of Innsbruck.

Conflict of interest B. Böttcher and K. Winkler-Crepaz declare that they have no competing interests.

Open Access This article is licensed under a Creative Commons Attribution 4.0 International License, which permits use, sharing, adaptation, distribution and reproduction in any medium or format, as long as you give appropriate credit to the original author(s) and the source, provide a link to the Creative Commons licence, and indicate if changes were made. The images or other third party material in this article are included in the article's Creative Commons licence, unless indicated otherwise in a credit line to the material. If material is not included in the article's Creative Commons licence and your intended use is not permitted by statutory regulation or exceeds the permitted use, you will need to obtain permission directly from the copyright holder. To view a copy of this licence, visit http://creativecommons.org/licenses/by/4.0/.

\section{References}

1. Li F, Turan V, Lierman S, Cuvelier C, De Sutter P, Oktay K. Sphingosine-1-phosphate prevents chemotherapyinduced human primordial follicle death. Hum Reprod. 2014;29:107-13. 
2. Zelinski MB, Murphy MK, Lawson MS, Jurisicova A, Pau KYF Toscano NP, et al. In vivo delivery of FTY720 prevents radiation-induced ovarian failure and infertility in adult female nonhuman primates. Fertil Steril. 2011;95:1440-1445.e1-7.

3. Kaya H, Desdicioglu R, Sezik M, Ulukaya E, Ozkaya O, Yilmaztepe A, et al. Does sphingosine-1-phosphate have a protective effect on cyclophosphamide- and irradiationinduced ovarian damage in the rat model? Fertil Steril. 2008;89:732-5.

4. Fisch B, Abir R. Female fertility preservation: past, present and future. Reproduction. 2018;156:F11-F27.

5. Gonfloni S, Di Tella L, Caldarola S, Cannata SM, Klinger FG, Di Bartolomeo C, et al. Inhibition of the c-Abl-TAp63 pathway protects mouse oocytes from chemotherapy-induced death. Nat Med Nat. 2009;15:1179-85.

6. Ting AY, Petroff BK. Tamoxifen decreases ovarian follicular loss from experimental toxicant DMBA and chemotherapy agents cyclophosphamide and doxorubicin in the rat. JAssist Reprod Genet. 2010;27:591-7.

7. Mahran YF, El-Demerdash E, Nada AS, Ali AA, AbdelNaim AB. Insights into the protective mechanisms of tamoxifen in radiotherapy-induced ovarian follicular loss: impact on insulin-like growth factor 1 . Endocrinology. 2013;154:3888-99.

8. Kalich-Philosoph L, Roness H, Carmely A, Fishel-Bartal M, Ligumsky H, Paglin S, et al. Cyclophosphamide triggers follicle activation and "burnout;" AS101 prevents follicle loss and preserves fertility. Sci Transl Med. 2013;5:185ra62.

9. Spears N, Lopes F, Stefansdottir A, Rossi V, De Felici M, Anderson RA, et al. Ovarian damage from chemotherapy and current approaches to its protection. Hum Reprod Update. 2019;25:673-93.

10. Donnez J, Dolmans M-M. Fertility preservation in women. NEngl J Med. 2017;377:1657-65.

11. Abir R, Fisch B, Jessel S, Felz C, Ben-Haroush A, Orvieto R. Improving posttransplantation survival of human ovarian tissue by treating the host and graft. Fertil Steril. 2011;95:1205-10.

12. Oktay K, Bedoschi G, Pacheco F, Turan V, Emirdar V. First pregnancies, live birth, and in vitro fertilization outcomes after transplantation of frozen-banked ovarian tissue with a human extracellular matrix scaffold using robot-assisted minimally invasive surgery. Am J Obstet Gynecol. 2016;214:94.e1-94.e9.

13. EppigJJ,O'Brien MJ.Development in vitro ofmouse oocytes from primordial follicles. Biol Reprod. 1996;54:197-207.

14. O’Brien MJ, Pendola JK, Eppig JJ. A revised protocol for in vitro development of mouse oocytes from primordial follicles dramatically improves their developmental competence. Biol Reprod. 2003;68:1682-6.

15. Liebenthron J, Köster M, Drengner C, Reinsberg J, van der Ven H, Montag M. The impact of culture conditions on early follicle recruitment and growth from human ovarian cortex biopsies in vitro. Fertil Steril. 2013;100:483-5.

16. Winkler-Crepaz K, Nederegger V, Ayuandari S, Rosenfellner D, Zervomanolakis I, Hofer S, et al. Novel dynamic culture system to support initiation of primordial follicle growth in prepubertal mouse ovaries. Fertil Steril. 2014;102:864-870.e2.

17. Telfer EE, McLaughlin M, Ding C, Thong KJ. A two-step serum-freeculturesystemsupports developmentofhuman oocytes from primordial follicles in the presence of activin. Hum Reprod. 2008;23:1151-8.

18. Jin SY, Lei L, Shikanov A, Shea LD, Woodruff TK. A novel two-step strategy for in vitro culture of early-stage ovarian follicles in the mouse. Fertil Steril. 2010;93:2633-9.
19. Martinez F, International Society for Fertility Preservation-ESHRE-ASRM Expert Working Group. Update on fertility preservation from the Barcelona International Society for Fertility Preservation-ESHRE-ASRM 2015 expert meeting: indications, results and future perspectives. Fertil Steril. 2017;108:407-11.

20. McLaughlin M, Albertini DF, Wallace WHB, Anderson RA, Telfer EE. Metaphase II oocytes from human unilaminar follicles grown in a multi-step culture system. Mol Hum Reprod. 2018;24:135-42.

21. Xiao S, Zhang J, Romero MM, Smith KN, Shea LD, Woodruff TK. In vitro follicle growth supports human oocyte meiotic maturation. Sci Rep Nat. 2015;5:17323-5.

22. Hsueh AJW, Kawamura K, Cheng Y, Fauser BCJM. Intraovarian control of early folliculogenesis. Endocr Rev. 2015;36:1-24.

23. Ayuandari S, Winkler-Crepaz K, Paulitsch M, Wagner C, Zavadil C, Manzl C, et al. Follicular growth after xenotransplantation of cryopreserved/thawed human ovarian tissue in SCID mice: dynamics and molecular aspects. J Assist ReprodGenet. 2016;33:1585-93.

24. Kawamura K, ChengY, Suzuki N, Deguchi M, Sato Y, Takae S, et al. Hippo signaling disruption and Akt stimulation of ovarian follicles for infertility treatment. Proc Natl Acad Sci USA. 2013;110:17474-9.

25. Kawamura K, Cheng Y, Sun Y-P, Zhai J, Diaz-Garcia C, Simon C, et al. Ovary transplantation: to activate or not to activate. Hum Reprod. 2015;30:2457-60.

26. Suzuki N, Yoshioka N, Takae S, Sugishita Y, Tamura M, Hashimoto S, et al. Successful fertility preservation following ovarian tissue vitrification in patients with primary ovarian insufficiency. Hum Reprod. 2015;30:608-15.

27. Winkler-Crepaz K, Böttcher B, Toth B, Wildt L, HoferTollinger S. What is new in 2017? Update on fertility preservation in cancer patients. Minerva Endocrinol. 2017;42:331-9.

28. Laronda MM, Jakus AE, Whelan KA, Wertheim JA, Shah RN, Woodruff TK. Initiation of puberty in mice following decellularized ovary transplant. Biomaterials. 2015;50:20-9.

29. Shea LD, Woodruff TK, Shikanov A. Bioengineering the ovarian follicle microenvironment. Annu Rev Biomed Eng. 2014;16:29-52.

30. Amorim CA, Shikanov A. The artificial ovary: current status and future perspectives. Future Oncol. 2016;12:2323-32.

31. Vanacker J, Dolmans M-M, Luyckx V, DonnezJ, Amorim CA. First transplantation of isolated murine follicles in alginate. Regen Med. 2014;9:609-19.

32. Luyckx V, Dolmans M-M, Vanacker J, Legat C, Fortuño Moya C, Donnez J, et al. A new step toward the artificial ovary: survival and proliferation of isolated murine follicles after autologous transplantation in a fibrin scaffold. Fertil Steril. 2014;101:1149-56.

33. Soares M, Sahrari K, Amorim CA, Saussoy P, Donnez J, Dolmans M-M. Evaluation of a human ovarian follicle isolation technique to obtain disease-free follicle suspensions before safely grafting to cancer patients. Fertil Steril. 2015;104:672-672.

34. Morohaku K, Tanimoto R, Sasaki K, Kawahara-Miki R, Kono T, Hayashi K, et al. Complete in vitro generation of fertile oocytes from mouse primordial germ cells. Proc Natl Acad Sci USA. 2016;113:9021-6.

35. Truman AM, Tilly JL, Woods DC. Ovarian regeneration: the potential for stem cell contribution in the postnatal ovary to sustained endocrine function. Mol Cell Endocrinol. 2017;445:74-84.

36. Donnez J, Squifflet J, Pirard C, Demylle D, Delbaere A, Armenio L, et al. Live birth after allografting of ovarian 


\section{short review}

cortex between genetically non-identical sisters. Hum Reprod. 2011;26:1384-8.

37. Dittrich R, Kliesch S, Schüring A, Balcerek M, BastonBüst DM, Beck R, et al. Fertility preservation for patients with malignant disease. Guideline of the DGGG, DGU and DGRM (S2k-level, AWMF registry no. 015/082, November 2017)_recommendations and statements for girls and women. Geburtshilfe Frauenheilkd. 2018;78:567-84.

Publisher's Note Springer Nature remains neutral with regard to jurisdictional claims in published maps and institutional affiliations.

- For latest news from international oncology congresses see: http://www.springermedizin.at/ memo-inoncology 